\title{
EL FUSILAMIENTO DE MAXIMILIANO DE HABSBURGO VISTO DESDE PARÍS. INEXACTITUDES Y REACCIONES EN LA PRENSA PERIÓDICA PARISINA
}

Samuel Iván García Bahena*

RESUMEN: La historiografía sobre el fusilamiento de Maximiliano de Habsburgo es abundante; sin embargo, se ha dejado de lado la recepción de la noticia en la prensa parisina. La desinformación y los rumores generaron toda suerte de especulaciones en los periódicos. Quizás por ello, la noticia causó más revuelo en París durante la Exposición Universal de 1867.

$$
\text { গ০) }
$$

THE EXECUTION OF MAXIMILIAN OF HABSBURG SEEN FROM PARIS. INACCURACIES AND REACTIONS IN THE PARISIAN PERIODICAL PRESS

ABSTRACT: The historiography on the execution of Maximilian de Habsburg is vast, nonetheless, the reception of the news in the Parisian press has been put aside. The disinformation and rumors generated all sorts of speculation in the newspapers. Maybe for this reason, the news had more impact in Paris during the Universal Exhibition of 1867.

PALABRAS CLAVE: Desinformación, Intervención francesa, prensa, Segundo Imperio mexicano KEY WORDS: Desinformation, French Intervention, press, Second Mexican Empire

RECEPCIÓN: 19 de enero de 2019.

APROBACIÓN: 10 de abril de 2019.

DOI: $10.5347 / 01856383.0131 .000296717$

* Licenciado en historia por la Facultad de Filosofía y Letras, UNAM. 
Se prohíbe su reproducción total o parcial por cualquier medio, incluido electrónico, sin permiso previo y por escrito de los editores. 


\section{EL FUSILAMIENTO DE \\ MAXIMILIANO DE \\ HABSBURGO VISTO \\ DESDE PARÍS. \\ INEXACTITUDES \\ Y REACCIONES \\ EN LA PRENSA \\ PERIÓDICA PARISINA}

El fusilamiento de Maximiliano de Habsburgo puede ser considerado el episodio más trágico del Segundo Imperio mexicano, ya que esa muerte inspiró cierto romanticismo entre sus contemporáneos e inclusive — en palabras de Konrad Ratz— hasta el día de hoy, "su trágico fin sigue siendo inspiración de obras literarias y de reflexiones históricas". ${ }^{1}$ Con el fusilamiento del emperador el 19 de junio de 1867 en el Cerro de las Campanas en Querétaro se dio punto final a la Intervención francesa, que había comenzado en 1862, y a la posibilidad de que México tuviera una monarquía como forma de gobierno.

La historiografía sobre el Segundo Imperio es abundante, como también los testimonios de nacionales y extranjeros que intentaron justificar o juzgar el fusilamiento del archiduque. ${ }^{2}$ En cambio, poco sabemos

${ }^{1}$ Konrad Ratz, Querétaro: fin del Segundo Imperio mexicano, 2005, México, Conaculta, p. 13.

${ }^{2}$ Sobre este punto, véase Martín Quirarte, Historiografía sobre el imperio de Maximiliano, 1970, México, Instituto de Investigaciones Históricas, UNAM; Erika Pani, Para mexicanizar el Segundo Imperio mexicano: El imaginario político de los imperialistas, 2001, México, El Colegio de México, Instituto de Investigaciones Dr. José María Luis Mora; y Olivia García de León Melo, "De historias contestatarias: El sitio de Querétaro y el fusilamiento de Maximiliano de Habsburgo a través de los escritos mexicanos y europeos de 1867 a 1869", tesis de licenciatura, 2006, México, Facultad de Filosofía y Letras, UNAM. 
sobre el seguimiento que la prensa europea hizo del sitio de Querétaro, la captura del monarca y su muerte. Se conocen menos las reacciones y las opiniones sobre estos acontecimientos en los periódicos parisinos.

El emperador Napoleón III recibió la noticia mientras el imperio celebraba la Exposición Universal de 1867. Los dignatarios más importantes del mundo se encontraban en la metrópoli francesa cuando se tuvo noticia del suceso. Las opiniones en la prensa periódica no se hicieron esperar.

De manera general, se sabe que la inmediata reacción a la noticia del juicio y fusilamiento de Maximiliano generó una indignación unánime en toda Europa. Sin embargo, lo que nos atañe en este momento es la recepción y el manejo de la noticia en los periódicos parisinos. ¿Cómo se manejó la noticia en un contexto en el que el Imperio francés se lucía en París con los asistentes a la Exposición Universal? ¿Se dio voz al fusilamiento con la misma intensidad en toda la prensa periódica parisina? Y si no, ¿por qué motivos?

\section{París y la Exposición Universal de 1867}

La Exposición Universal de París fue inaugurada el $1^{\circ}$ de abril de 1867 , para demostrar el progreso de la industria y el desarrollo en las vías económicas, artísticas y culturales. El Campo Marte, antiguo campo de entrenamiento militar, fue la sede principal. El arquitecto Léopold Hardy había construido un recinto de 35 toneladas en donde se albergó a más de 50000 expositores provenientes de todo el mundo. ${ }^{3}$ Se construyeron parques, jardines y espacios que invitaban a la recreación de los asistentes. La sede también se conectaba mediante trasbordadores de vapor con la isla de Billancourt, que fue un lugar alterno dedicado a exponer los progresos industriales en la agricultura. ${ }^{4}$ Con la exposición el imperio

${ }^{3}$ De estos, 16000 eran franceses, 28400 europeos y el resto provenía de diferentes partes del mundo. Adolphe Démy, Essai historique sur les expositions universelles de Paris, 1907, París, Librairie Alphonse Picard et fils. Esta nota y las siguientes tomadas de fuentes francesas son traducción mía.

${ }^{4}$ La zona de Billancourt se halla al poniente de París, sobre el río Sena. 
invitaba a europeos y americanos a ser testigos de las mejoras tecnológicas. ${ }^{5}$

Desde abril hasta octubre de ese año, París se convirtió en la anfitriona de Europa, "la posada de las naciones". Los hoteles en la ciudad alojaron a más de 600000 visitantes. Los precios se volvieron exorbitantes: "se pagaba por doquiera y por todo". ${ }^{6}$ Se ofrecía comida de todo tipo y la ciudad se convirtió en una urbe muy animada, festiva y ruidosa. ${ }^{7}$ Los asistentes también pudieron disfrutar una ciudad moderna y remodelada: se restrenaron bulevares, avenidas y paseos que habían estado a cargo del prefecto de la ciudad, el barón Haussmann. Aumentaron los coches de plaza, lo que facilitó los traslados de los visitantes. Además, los asistentes hallaron numerosas actividades culturales: "La afluencia y el ambiente creados por la exposición estimularon también la actividad en los teatros" y en los cafés de la ciudad. ${ }^{8}$ La satisfacción del emperador fue tal, que hizo pública la carta de felicitación que dirigió al prefecto de la policía parisina por el orden con que se había celebrado el encuentro. 9

El enorme palacio que construyó Léopold Hardy como sede principal tenía forma ovalada (a manera de estadio) y era tan fácil de desarmar

${ }^{5}$ Napoleón III, Discurso del 25 de enero de 1863, en Marie Galvez, “L'Exposition universelle de 1867 à la Bibliothèque impériale", Le Blog Gallica, 17 de agosto de 2018, disponible en <https:// gallica.bnf.fr/blog/17082017/lexposition-universelle-de-1867-la-bibliotheque-imperiale>, consultado en julio de 2018.

${ }^{6}$ Victor Fournel, "Voyage à travers 1'Exposition universelle. Correspondant du 25 avril 1867", p. 984 , ibid., p. 148.

${ }^{7}$ Le Petit Journal, p. 1. En los restaurantes y cafés se vendían postres y platillos internacionales, como roastbeef inglés, arroz turco condimentado, quesos suizos, jamones alemanes, etcétera.

${ }^{8}$ Jean-Charles Geslot, "La vie parisienne, entre culture et politique: l'exemple de l'Exposition Universelle de 1867”, La vie parisienne, une langue, un mythe, un style (2007), p. 2, disponible en $<\mathrm{http}$ ///etudes-romantiques.ish-lyon.cnrs.fr/wa_files/Geslot.pdf>, consultado en julio de 2018.

${ }^{9}$ Le Temps, 30 de junio de 1867, p. 3. "Palacio de las Tullerías, 29 de junio de 1867: Mi querido monsieur Pietri, la presencia durante estos últimos días, en París, de muchos de los soberanos, y el concurso de una masa numerosa atraída por el espectáculo de la Exposición Universal, fue para el servicio dejado a sus órdenes la ocasión de mostrar que está a la altura de la tarea importante que se le ha confiado. Pude reconocer por mí mismo la sensatez de las medidas tomadas para asegurar sobre todos los puntos el mantenimiento del buen orden y constaté con placer el celo y la excelente vestimenta de sus agentes. Tengo que expresarle mi satisfacción y le ruego de ser el portavoz junto con vuestro personal. Reciba, querido señor Pietri, la seguridad de mis sentimientos de amistad. [Firmado] Napoleón.” 
como rápido de ensamblarse. El arquitecto lo había dotado de pequeños canales de hierro fundido que recolectaban el agua de lluvia y la llevaban a diferentes zonas de la ciudad parisina. ${ }^{10}$ En el nuevo recinto se expusieron diferentes temas: obras de arte, instrumentos musicales, muebles y objetos de habitación, vestimenta, productos industriales, alimentos y nuevas máquinas para tejidos. ${ }^{11}$ También había artículos para agricultura y horticultura, utensilios (como los destinados a la enseñanza escolar) y un pabellón que exponía "la historia del trabajo" y de la "economía social". ${ }^{2}$

París se convirtió en un destino vacacional y el Imperio francés mostró el progreso industrial y civilizatorio del que se consideraba abanderado en Europa. Napoleón III aprovechó también la exposición como propaganda política: se reforzó al régimen con la imagen de un imperio próspero que mostraba al mundo "la excelencia de la civilización francesa" y sus logros. ${ }^{13}$ Se debía legitimar al gobierno frente a aquellos que lo desprestigiaban. Por ejemplo, la oposición republicana (con el periódico Le Siècle como portavoz) atacó al régimen por sus excesos en las festividades de la exposición y su alto costo. La prensa atacaba al imperio, pero tuvo el cuidado de no censurar de manera abierta a la Exposición Universal de 1867. No todos los miembros del republicanismo francés reprobaban el encuentro y algunos lo vieron como muestra de paz entre naciones que habían estado en guerra de manera reciente, por ejemplo, la guerra germano-danesa de 1864 y la guerra austro-prusiana de $1866 .{ }^{14}$

${ }^{10}$ Casalonga, Palais de l'exposition universelle de 1867, 1868, Saint-Nicolas, P. Trenel.

${ }^{11}$ Michel Alcan, Études sur les arts textiles à l'exposition universelle de 1867 comprenant les perfectionnements récents apportés, 1868, París, Librairie polytechnique de J. Baudry.

${ }^{12} \mathrm{Ibid}$., p. 126. Es interesante observar que la "historia del trabajo" (muy ad hoc con el progreso industrial de la época) fue dividida en diez épocas: la Galia antes de los metales, la Galia independiente, la Galia durante la dominación romana, la Francia carolingia, los Carlovingios en los siglos X-XI, la Edad Media del siglo XII hasta el fin del reinado de Luis XI, el renacimiento desde Carlos VIII hasta la muerte de Enrique IV, los reinados de Luis XIII y de Luis XIV (1610-1715), el reinado de Luis XV (1715-1775), y del reino de Luis XVI a la Revolución (17751800). Démy, op. cit., p. 148.

${ }^{13}$ Geslot, op. cit., p. 3.

${ }^{14}$ El diario anunció que el éxito de la exposición había incrementado la popularidad de la revista ilustrada l'Exposition Universelle illustrée de 1867. El interés del público fue tal, que se agotaron todos los números. Es curioso que un diario republicano hiciera propaganda a una 
No obstante el ambiente festivo, hubo parisinos descontentos con el hecho de que los hoteles y cafés de la ciudad estuvieran abarrotados de extranjeros. La locura desbordada y los precios exagerados quedaron plasmados en la opinión (o queja) de un columnista de Le Monde Illustré:

Qué multitud y qué invasión, iy se dice que esto no es nada aún! Miren frente a ustedes, atrás de ustedes, a la derecha, a la izquierda. He aquí a los ingleses, a los rusos, a los valacos, a los italianos, a los tailandeses, a los manchúes, a los alemanes y los iowas. Los artilleros de Greenwich y los fusileros pomeranos avanzan sobre nuestros bulevares, los húngaros con sus botas [...]. Todas las repúblicas del Ecuador están aquí $[\ldots]$ y todas las islas de Oceanía, todas las naciones, todos los colores, todas las pieles están representadas. Ya no es París, es Babel. El bulevar ya no es transitable, es necesario escapar y no vendrán tiempos mejores. ${ }^{15}$

Los testimonios demostraban que la exposición fue pensada para las clases más acomodadas (para magnates, en opinión del columnista). Para un parisino común era imposible aventurarse a la exposición y gastar ahí. A pesar de ello, los asistentes no dejaban de concurrir a la capital francesa y atestar las principales calles y edificios. Monarcas

publicación oficialista (la revista estaba autorizada por la Comisión Imperial). Además, uno de sus redactores había sido Michel Chevalier, personaje muy cercano a Napoleón III y que había promovido desde época temprana una intervención en América Latina, específicamente en México, para frenar la expansión territorial y económica de los Estados Unidos. Le Siècle, 3 de junio de 1867 , p. 3. Garnier-Pagès juzgaba que los soberanos invitados y reunidos en París durante la Exposición, "no habían cenado juntos para traicionarse o para prepararse a empapar de sangre nuevos campos de batalla". Cfr. "Journal des débats politiques et littéraires", $1^{\circ}$ de julio de 1867, ibid.p. 9. De acuerdo con Geslot, el asunto de la exposición fue uno de los pocos que no impugnaron los republicanos en el Cuerpo Legislativo. Al parecer, hubo una especie de tregua entre opositores y partidarios del imperio.

${ }^{15}$ Le Monde Illustré, 6 de abril de 1867, p. 210. El autor también se quejó de "los precios exagerados" de la exposición. Aunque hubo pabellones con exposiciones gratuitas, fueron las menos. Además se debía gastar en el transporte o renta de coche, de ida y vuelta, alimentos y entradas para los más de 300 pabellones expositores. Por ellas se debía pagar entre 25 céntimos y un franco. Una persona modesta y con familia jamás hubiera podido asistir. 
y representantes invitados por el gobierno imperial recorrían gustosos la urbe. ${ }^{16}$ París y el Campo Marte encarnaban el lema de la exposición: "El progreso y la paz". ${ }^{17}$

La fiesta y el lujo de aquellos meses hacían olvidar los problemas políticos de Europa y del imperio; por ejemplo, el reciente fracaso de la expedición francesa en México. ${ }^{18}$ A inicios de 1867, las últimas tropas francesas se habían embarcado rumbo a Francia, dejando solo a Maximiliano de Habsburgo. Cuando inició el sitio de Querétaro, la prensa periódica en París tuvo pocas e inexactas noticias de lo que ocurría en México, y la desinformación sobre la noticia generó una ola de absurdos rumores. Quizás por ello se le dio tan poca importancia en un primer momento. En realidad, con la Exposición Universal y los dignatarios asistentes, las páginas de los periódicos parisinos centraban su atención en Europa en los primeros meses de 1867. Sin embargo, cuando se supo que Maximiliano había sido derrotado y capturado en Querétaro, los encabezados parisinos se asomaron de nuevo a lo que ocurría allende el Atlántico.

\section{Opiniones y reacciones de la prensa francesa}

A partir de junio de 1867, las noticias fueron llegando a cuentagotas y, las más de las veces, con información errónea. Enseguida se suscitó un interés general por saber si el archiduque regresaría a Europa o hallaría la muerte en México. La prensa periódica, que había estado dedicada

${ }^{16}$ A París habían asistido "el zar Alejandro [II] de Rusia, el canciller Bismarck, el sultán de Turquía, reyes, reinas, mandatarios gobernantes, diplomáticos, en fin, poco más de 80 personalidades ahí reunidas junto con su glamour y sus vanidades". Isaí Hidekel Tejeda Vallejo, "El fusilamiento de Maximiliano de Habsburgo", disponible en <http://www. diputados.gob.mx/sedia/biblio/virtual/bicentena/fusil_max/03_fusil_maxil.pdf $>$.Consultado en julio de 2018 .

${ }^{17}$ Loc. cit.

${ }^{18}$ No todo había sido glamur y felicidad: hubo en 1867 brotes de cólera e inundaciones en París. Además, desde inicios de año había habido un invierno gélido que se extendió más allá de la primavera. Por si fuera poco, el zar Alejandro II de Rusia sufrió un atentado de un obrero polaco durante su estancia, incitado por el dominio ruso sobre Polonia. Turgan, Études sur l'exposition universelle, 1867, 1867, París, Michel Lévy frères. 
a otros asuntos, comenzó a mirar hacia México, en un intento por dar a los lectores una explicación satisfactoria del desenlace del emperador. ${ }^{19}$

Los diarios transmitían las noticias de acuerdo con sus intereses políticos. La derrota y captura de Maximiliano no interesó a todas las fuentes hemerográficas de la misma manera ni tampoco le dieron la misma importancia. Así, mientras algunos dedicaban secciones especiales a continuar hablando sobre la Exposición Universal y la vida parisina (como la revista ilustrada Le Monde Illustré) y reservaban pocas líneas a la situación mexicana, otros la callaban. Los diarios más liberales intentaron informar la suerte que corría el emperador Maximiliano a pesar de las contradicciones en las noticias que se recibían. Todos los que se interesaron por el monarca de México manifestaron gran interés por que regresara pronto a Europa.

Para comprender la recepción e impacto del fusilamiento de Maximiliano de Habsburgo en la prensa francesa, es necesario clasificar las fuentes hemerográficas en grupos temáticos. Los periódicos de la época publicaron, de manera muy variada y hasta contradictoria, diversos aspectos y opiniones sobre México y su emperador. Grosso modo, los temas pueden resumirse en: noticias complementarias al sitio de Querétaro, la derrota de Maximiliano y la traición del oficial imperial Miguel López (bastante atacado en estos ejemplares). También hubo gran interés en la posible intervención diplomática de Estados Unidos para asegurar la vida del archiduque. Igualmente, se publicó la discusión de los gastos de l'Expédition du Mexique en el Cuerpo Legislativo, con saldo deficitario que recibió el reproche de la oposición republicana. Se dedicaron espacios para referirse al presidente Juárez con tintes negativos y hasta despectivos. Las expectativas sobre la suerte de Maximiliano (por ejemplo, su liberación y rembarco) generaron informes apócrifos que alentaron la esperanza entre los diarios referidos.

${ }^{19}$ En la prensa francesa había columnistas, editores y directores de las más variadas opiniones políticas, que reflejaron en los diarios. Así, unos periódicos eran de tendencia republicana; otros, monarquistas gobiernistas; algunos más, liberales sin compromiso con el Imperio francés. Para más información sobre la prensa francesa durante esta época, véase Claude Bellanger, Histoire générale de la presse française, 1969, París, Presses Universitaires de France, p. 258. 


\section{Interés en el sitio de Querétaro y la suerte de Maximiliano}

Como vimos, las noticias publicadas sobre el archiduque variaban según el diario. Por ejemplo, Le Constitutionnel, Le Temps y Le Petit Journal fueron, al menos en un primer momento, los menos interesados en el sitio de Querétaro y Maximiliano. Es cierto que la prensa carecía de notificaciones oficiales, pero quizá sus intereses simplemente estaban en otros temas. El periódico Le Constitutionnel fue un diario legitimista gobiernista que contaba entre sus accionistas a un medio hermano de Napoleón III (el duque de Morny), lo que lo convertía en portavoz del imperio. ${ }^{20}$ Tal vez por ello aportó pocas noticias sobre Maximiliano: así se evitaría comprometer al Imperio francés con la suerte del archiduque que había dejado en México. Los diarios Le Temps y Le Petit Journal eran "liberales y modernos", mas no opositores declarados del régimen. Aunque el primero informaba a sus lectores lo que acontecía en el extranjero y el segundo tocaba temas políticos sin ofrecer un análisis profundo, ambos se mantuvieron al margen y apenas publicaron nada sobre Maximiliano. Su interés aumentó solo cuando se confirmó la noticia de su muerte.

De manera general, la lentitud con la que se transmitían las noticias de México (principalmente desde Nueva York y Nueva Orleans hacia París, Londres y Viena) hizo que al principio la prensa creyera que Maximiliano había salido victorioso de la contienda contra los juaristas en Querétaro: "El día mismo que el gobierno francés recibía la noticia de la captura de Maximiliano, algunos diarios oficiosos de París anunciaban la gran derrota de los republicanos". ${ }^{21}$ El gobierno recibió un telegrama procedente de Washington el 31 de mayo de 1867, que confirmaba la rendición del archiduque. La derrota había ocurrido el 15 de mayo. En un primer instante se ignoraron los detalles de la victoria republicana y se esperaba que el gobierno estadounidense intercediera por la vida del emperador. ${ }^{22}$

${ }^{20}$ Samuel Iván García Bahena, "La capital intervenida: ocupación militar de la ciudad de México durante la Intervención francesa”, tesis de licenciatura en historia, 2018, México, Universidad Nacional Autónoma de México.

${ }^{21}$ Le Siècle, 10 de junio de 1867, p. 1.

${ }^{22}$ Le Siècle, 5 de junio de 1867, p. 1. Por ejemplo, no se comunicó en un inicio sobre la supuesta traición del oficial imperial Miguel López. 
A partir de la primera semana de junio, tras la publicación del telegrama (que también se dio a conocer en la Gazette de Vienne), la prensa parisina retomó el interés por el inminente fin del imperio mexicano y su monarca. A pesar de que se acumulaban los despachos telegráficos que confirmaban la noticia, algunos diarios consideraron falsa la victoria juarista. El Courrier des Etats-Unis (diario esclavista durante la guerra de secesión estadounidense y que apoyó la causa de Maximiliano) no otorgó crédito a la derrota y concedió el triunfo en Querétaro a los imperialistas. ${ }^{23} \mathrm{El}$ enredo de noticias hacía difícil saber la verdad. Le Figaro (diario moderno y liberal en el que colaboraron autores como Balzac, Baudelaire y Dumas) también informó sobre un supuesto fracaso de los liberales republicanos en México y de la huida de Juárez. ${ }^{24}$ Por su parte, el Messager Franco-Américain señaló que la noticia de la victoria republicana en México podría tratarse de una artimaña del partido liberal para desmoralizar a los partidarios del Imperio mexicano. Además, consideró falso el rumor de que el emperador Maximiliano sería fusilado. ${ }^{25}$

Al paso de los días, las comunicaciones comenzaron a certificar que Maximiliano se encontraba en poder de los republicanos. Uno de los periódicos que más noticias publicó al respecto fue Le Journal de Débats (de tendencia monarquista, mas no partidario de Napoleón III), que mediante la Gazette de Vienne informó cómo tomaron Querétaro los republicanos durante la madrugada del 15 de mayo de 1867 y que el Convento de la Cruz, donde resistía el ejército imperial, fue asaltado por sorpresa desde muy temprano. La situación había obligado a Maximiliano a huir al Cerro de las Campanas, donde se rindió a discreción

${ }^{23}$ Esta especie fue transmitida desde La Habana por el Diario de la Marina, que además anunció que Maximiliano, victorioso del sitio de Querétaro, se dirigía a la ciudad de México con 8000 hombres, para arrebatarla al general republicano Porfirio Díaz. Journal des Débats, 3 de junio de 1867, p. 1. La nota también se reprodujo en Le Temps, $1^{\circ}$ de junio de 1867, p. 1.

${ }^{24}$ Le Figaro, $1^{\circ}$ de junio de 1867, p. 2.

${ }^{25}$ Ambas opiniones fueron citadas en Le Siècle, 10 de junio de 1867, p. 1, y persistieron a pesar de que se había publicado la carta de felicitación del presidente Benito Juárez al general republicano Felipe Berriozábal: "San Luis Potosí, 15 de mayo de 1867: Al general Berriozábal. Mi estimado amigo, ¡Viva la patria! Querétaro ha sido tomado a viva fuerza esta mañana a las 8 horas. Maximiliano, Mejía, Castillo y Miramón son presos. Benito Juárez”. Loc. cit. 
junto con sus generales. Para entonces, los Estados Unidos habían solicitado al presidente Juárez un trato humanitario al emperador vencido, una petición a la que se sumaron los diarios parisinos. ${ }^{26}$ Durante junio de 1867 aumentaron la cantidad y el detalle de los informes que publicaba la prensa. Lo siguiente que interesó a la opinión pública parisina fue que el archiduque salvara la vida. Se consideraba que el único que podía perdonarlo era el mismo presidente Juárez y se esperaba que interviniera el representante estadounidense Campbell. ${ }^{27}$ Se pensaba que la intercesión de los estadounidenses era vital si se quería salvar al emperador de México. ${ }^{28}$

Los periódicos publicaron informes y despachos contradictorios, alimentados por la esperanza de que Maximiliano de Habsburgo regresara sano y salvo a Europa después de haber ocupado el trono mexicano por tres años. Los rumores de que el hermano del emperador de Austria conservaría la vida crecieron aceleradamente. Los diarios que publicaron más información errónea fueron Le Journal des Débats, Le Temps y Le Figaro. Se debió probablemente a que sus fuentes no eran las mejores: bastaba que un diario publicara una noticia, errónea o no, para que cundiera entre los periódicos restantes. Así, la creencia de que Maximiliano sería desterrado de México y embarcado hacia Europa fue un rumor que poco a poco cobró fuerza. Por ejemplo, Le Siècle informó que de acuerdo con L'Étendard de Bruselas, el archiduque había sido condenado al exilio por las autoridades mexicanas y desembarcaría próximamente en Inglaterra. ${ }^{29}$ En los mismos términos, Le Cons-

${ }^{26}$ Le Journal des Débats, 5 de junio de 1867, p. 1. A manera de anécdota, por analogía se comparó la lucha entre la Republica y el Imperio mexicano con la guerra de secesión estadounidense de 1865, en la que al vencer la Unión a los estados Confederados se perdonó la vida del líder sureño Jefferson Davis. La prensa parisina reprochó a Juárez, en quien se vio a un personaje inflexible e incapaz de mostrar clemencia con Maximiliano, que no hubiera aprendido la "lección".

${ }^{27}$ Journal des Débats, 14 de junio de 1867, p. 1.

${ }^{28} \mathrm{El}$ tema fue muy debatido. Le Siècle, Le Figaro, Le Constitutionnel y Le Journal des Débats abrigaban la esperanza de que una enérgica intervención diplomática orillaría a Juárez a mostrar clemencia.

${ }^{29}$ Le Siècle, 25 de junio de 1867, p. 1. El periódico comunicó la noticia en estos términos: "Un despacho telegráfico de M. Seward a la legación estadounidense en Viena anuncia que el emperador Maximiliano fue condenado al exilio, que ha partido para Europa y que desembarcará en Inglaterra". 
titutionnel señaló el 24 de junio de 1867: "Hoy podemos dar nuevas un poco más certeras de la situación del emperador Maximiliano. Según información que tendemos a creer exacta, el emperador Maximiliano se va a embarcar o ya se ha embarcado para Europa". ${ }^{30}$ En opinión de estos diarios, el pronto regreso del emperador de México "sería la única solución humana y verdaderamente política que puede recibir este episodio del drama mexicano". ${ }^{31}$ Los informes llegados sobre México eran cada vez más alarmantes. No se tenía plena certeza de que Maximiliano de Habsburgo sería juzgado y condenado a muerte, pero tampoco era del todo seguro que fuera indultado y enviado a Europa. ${ }^{32}$

Se quería creer que el gobierno mexicano de Juárez y Lerdo de Tejada no se atrevería a actuar en contra de los deseos de la mayoría de la opinión pública europea. Como si de un tormento pasajero se tratara, y no de una posibilidad real, se quiso hacer oídos sordos a la noticia de que el archiduque y sus generales serían pasados por las armas. En opinión del Messager Franco-Américain, la presión diplomática de Estados Unidos, de Francia, de Austria y aun de Rusia sería suficiente para garantizar la vida de Maximiliano. Inclusive hubo quienes señalaban que el presidente Juárez ya se había comprometido ante las potencias europeas a salvar la vida del monarca vencido. ${ }^{33}$ Se quería difundir la noticia de que se estaba haciendo hasta lo imposible para que se le dejara en libertad. De hecho, por entonces también se habló en la prensa parisina sobre el supuesto "rescate" que Juárez ("el salvaje triunfador" como lo llamó Le Temps) había exigido para su liberación. Se habló de la cantidad de 62 millones y medio de francos. ${ }^{34}$

Frente a la aparente resistencia de la prensa a creer en la condena de Maximiliano, se produjo también una ola repentina de comunicados que

${ }^{30}$ Le Constitutionnel, 24 de junio de 1867.

${ }^{31}$ Le Siècle, 19 de junio de 1867. Curiosamente, esta nota se publicó el mismo día del fusilamiento de Maximiliano.

${ }^{32}$ Sobre lo cambiante de las noticias, Le Figaro publicó: "la última palabra sobre el terrible drama de México puede, de un instante al otro, cambiar a duelo todas estas alegrías oficiales. Las nuevas noticias venidas de ese lado son cada vez más alarmantes". Le Figaro, 6 de junio de 1867 , p. 3.

${ }^{33}$ Le Figaro, 10 de junio de 1867, p. 3.

${ }^{34}$ Le Temps, 7 de junio de 1867, p. 1. 
confirmaban su deceso en Querétaro. Se informaba del "asesinato" del emperador de México y, casi de inmediato, se desmentía la información. La misma suerte corrían los generales imperiales Miramón, Mejía y Castillo. Le Temps opinó sobre este constante estado de desinformación:

Según los últimos avisos recibidos de México en Nueva York, el general Miramón, que el cable y los diarios estadounidenses han matado y resucitado tantas veces, habría decididamente, muerto de fiebre. Los generales Mejía y Castillo, que se habían rendido a discreción con Maximiliano, después de la caída de Querétaro, habrían sido fusilados. El despacho calla sobre la suerte reservada al exemperador de México. ${ }^{35}$

Hasta ese momento, ni Miramón había muerto de fiebre - aunque sí había recibido una herida en el rostro - ni Mejía había sido fusilado. La falta de informes oficiales propiciaba que se hicieran conjeturas erróneas sobre el emperador y sus generales. Nuevos despachos provenientes de Nueva York transmitieron que Maximiliano había sido conducido por las tropas republicanas a la capital mexicana como prisionero de guerra, cuando, en verdad, nunca salió de Querétaro. ¿Por qué se publicó esta noticia? Una explicación parcial sería que se creyó que en un intento por provocar la rendición de la ciudad de México, que por entonces, aún se resistía a capitular ante el general Porfirio Díaz que la mantenía sitiada, conducir a Maximiliano como prisionero sería el primer paso para negociar su posible liberación. Así lo señaló el Mémorial Diplomatique y consideró que el traslado a la capital era una garantía de su salvación, pues de esta manera el gobierno mexicano podría cobrar el supuesto rescate exigido:

En los círculos políticos, se considera generalmente el traslado del emperador Maximiliano a México como una nueva prueba de que los disidentes respetarán su vida. Suponemos que este desgraciado soberano será conducido de México a Veracruz, desde donde podrá ser embarcado, sea

${ }^{35}$ Le Temps, 15 de junio de 1867, p. 1. 
hacia Estados Unidos, sea para Europa. Es verdad que el gobierno juarista demandó un rescate. Pero no es cierto que, en nuestro conocimiento, el precio haya sido debatido entre las partes interesadas. Esta cuestión es, al menos, completamente secundaria concerniente al interés que hay por parte de Austria y de Francia de que la vida del emperador Maximiliano sea respetada. ${ }^{36}$

Apenas el 27 de junio de 1867 publicó el Mémorial Diplomatique que había telegramas y noticias apócrifas concernientes a la suerte del emperador, de ahí la creciente ola de rumores y falsas expectativas. Solo entonces las especulaciones que aseguraban que el monarca de México ya se había embarcado a Europa o sería perdonado dejaron de tener fuerza en la opinión pública. ${ }^{37}$ ¿De dónde habían salido estos informes falsos y quién los había escrito? Ninguna fuente hemerográfica da la respuesta. Quizá haya que estudiar a fondo las redes de comunicación de esta prensa para llegar a un resultado parcial.

Esos rumores cedieron el paso a otros, menos esperanzadores. Así, el periódico Le Temps señaló que Maximiliano sería juzgado a puerta cerrada por un consejo de guerra ordinario "de la misma manera que se juzgaba a un criminal". La correspondencia que el diario citó, concerniente a la prensa estadounidense, entre el ministro Campbell y Lerdo de Tejada, así lo señalaba. A Maximiliano se le denominó el "nuevo Iturbide", en alusión al primer monarca mexicano que también había sido fusilado. ${ }^{38}$ Por el contrario, en opinión del Journal des Débats, el hecho de que el emperador de México fuera juzgado por un consejo de guerra no significaba necesariamente que lo fusilarían. A pesar de la crítica situación, el diario mantenía la esperanza de que el juicio solo fuera una mera formalidad y de que el monarca fuera enviado a Europa. "Es preciso esperar que Juárez no quiera cargar con tan grande responsabilidad." 39

${ }^{36}$ Le Mémorial Diplomatique, citado en "Le Journal des Débats", 12 de junio de 1867, p. 1.

${ }^{37}$ Le Mémorial Diplomatique, 27 de junio de 1867, p. 1.

${ }^{38}$ Le Temps, 17, 19 y 22 de junio de 1867.

${ }^{39}$ Le Journal des Débats, 13 de junio de 1867, p. 1. 


\section{Certeza del fusilamiento}

Las expectativas de que Maximiliano de Habsburgo fuera indultado y se embarcara hacia Europa fueron muchas; realmente se creyó que regresaría vivo a Austria. Estas esperanzas no fueron privativas de los abogados mexicanos que intentaron obtener el perdón del presidente Juárez en México, desde Querétaro y San Luis Potosí. ${ }^{40}$ Y lo mismo que sus defensores en México, el interés porque el monarca conservara la vida también recorrió los ejemplares hemerográficos parisinos. Una vez que se tuvo la certeza de que el gobierno mexicano había juzgado, condenado y fusilado al archiduque de Austria, se le calificó de "crimen de lesa majestad", de crimen atroz. ${ }^{41}$

De acuerdo con Konrad Ratz, pocos periodistas atestiguaron el proceso de Maximiliano en Querétaro. El único reportero mexicano presente fue Luciano Frías y Soto, director del periódico La Sombra de Arteaga, cuya crónica se publicó el 16 de junio de 1867. Por parte de los Estados Unidos, asistió Clark del New York Herald, quien se limitó a enviar una versión en inglés del artículo de Soto. ${ }^{42}$ Así las cosas, sería comprensible que en París las noticias sobre el juicio y la ejecución hayan llegado con muchos días de retraso. Ratz también señaló que el despacho telegráfico que confirmaba la muerte de Maximiliano se dio a

${ }^{40}$ Los abogados mexicanos que intercedieron en San Luis fueron Mariano Riva Palacio y Rafael Martínez de la Torre, así como también Inés y Félix de Salm-Salm. Otros defensores oficiosos que intercedieron por Maximiliano ante Juárez fueron el vicecónsul de las ciudades hanseáticas, John Bahnsen; Jesús María Vázquez Palacios, rector del colegio de jesuitas en Querétaro, quien trató de ganar tiempo para que las potencias europeas interviniesen; Frédéric Hall, juez y jurista estadounidense que propuso la idea de la inconstitucionalidad de la ley del 25 de enero de 1862, que adoptaron los abogados de Maximiliano; Ratz, op. cit., p. 253. También intercedió Anton von Magnus ministro de Prusia en México, quien relató en sus memorias lo difícil de solicitar al gobierno mexicano la entrega del cadáver del archiduque, labor que nunca consiguió. Sus memorias están publicadas en Konrad Ratz (comp.), El ocaso del imperio de Maximiliano visto por un diplomático prusiano: Los informes de Anton von Magnus a Otto von Bismarck 1866-1867, 2011, México, Siglo XXI.

${ }^{41}$ Le Temps, 8 de julio de 1863, p. 1.

${ }^{42}$ Ratz, Querétaro, pp. 308-309. 
conocer el $1^{\circ}$ de julio de $1867 .{ }^{43}$ Sin embargo, tuvieron que pasar algunos días más para que la noticia se publicara en los periódicos parisinos. ¿Explicaría esta tardanza cierta cautela de la prensa parisina, en medio de especulaciones y rumores falsos? Hasta este momento, nada apunta a que haya habido ninguna censura del Imperio francés.

Entre el 4 y 5 de julio de 1867 la noticia se esparció. Se denostó a México y al presidente Juárez de manera unánime. En el gobierno republicano se buscó y se halló a los culpables de la muerte del archiduque. Por ejemplo, para Le Constitutionnel "el crimen" finalmente había sido cometido y Maximiliano había sido víctima de una "odiosa venganza" alentada por el gobierno mexicano: "El drama comenzó por la traición, terminó en asesinato". ${ }^{44}$ El periódico también publicó las sesiones del Senado y del Cuerpo Legislativo francés, en las que se dijo que "Juárez es un verdugo y Maximiliano es una víctima". ${ }^{45}$ El presidente del Senado apuntó que no dudaba que la sangre del emperador de México recaería sobre aquellos que la habían derramado, es decir, sobre el partido republicano y su presidente. Los improperios contra los mexicanos se generalizaron en la prensa parisina y se señaló también como primeros culpables, al "traidor" Miguel López — presunto culpable de haber entregado el baluarte a las tropas del general Escobedo-y a Juárez, quien no quiso otorgar el indulto al archiduque austriaco. ${ }^{46}$

Las condolencias en la prensa por la muerte del Habsburgo no escasearon y se señaló la tristeza que recorrió las casas reinantes europeas. Los periódicos también dieron a conocer el duelo que declaró la corte de Viena y el emperador de Austria, Francisco José, hermano de Maximiliano. E1 2 de julio, el monarca austriaco recibió la noticia del fusilamiento en Bruselas e inmediatamente regresó a Viena “en un tren especial". ${ }^{47}$ La prensa parisina en general temió que el suceso afectara

${ }^{43}$ Ibid., p. 363.

${ }^{44}$ Le Constitutionnel, 5 de julio de 1867, p. 1.

${ }^{45}$ Ibid., 6 de julio de 1867, p. 1.

${ }^{46}$ Loc. cit.

${ }^{47}$ Le Temps, 4 de julio de 1867, p. 1. 
las futuras relaciones entre Francia y Austria, dado que Napoleón III había impulsado la Intervención francesa en México y las armas francesas habían sostenido y abandonado a Maximiliano. ${ }^{48}$

A cuentagotas llegaron telegramas desde Nueva York que completaron las noticias del fusilamiento, y con ellas también se retomó el tema del sitio de Querétaro y se trató de reconstruir y difundir en la prensa los últimos días que vivió el emperador de México. Los diarios parisinos también ensalzaron su figura como "el legítimo monarca" de México (reconocido por todas las monarquías y "elegido" por los mexicanos) y su suerte se comparó una vez más con la de Agustín de Iturbide, el primer emperador mexicano fusilado en 1824.

La culpa recaía en Juárez. Le Figaro opinó que con su muerte, se había hecho de Maximiliano un héroe y un mártir. ${ }^{49}$ Ninguna publicación mencionó ni reprochó al Imperio francés su actuación durante la Intervención francesa. Ningún periódico señaló como culpable a Napoleón III por haber abandonado a Maximiliano en tierras mexicanas. Por el contrario, se opinó que el emperador de México había tenido la oportunidad de regresar a Europa junto con el mariscal Achilles Bazaine y el resto de sus tropas. En esta crítica moderada, tampoco se acusó al archiduque de necedad; antes bien, se opinó que se había quedado en el trono mexicano porque había querido defender a quienes habían creído en su causa. La mala suerte del monarca radicó en no haber contado con la traición de Miguel López. ${ }^{50}$ Le Mémorial Diplomatique defendió a Maximiliano contra quienes señalaron que el monarca había sellado su fin al decretar, "forzado por las circunstancias", la ley del 3 de octubre de 1865, mediante la cual se había proscrito a los guerrilleros mexicanos que habían seguido combatiendo al Imperio. ${ }^{51}$

${ }^{48}$ De hecho, en julio de 1867 los emperadores de Austria visitaron la Exposición Universal de Paris. La prensa francesa se preocupó por la situación incómoda de la noticia de la muerte de Maximiliano en el momento justo en que se esperaba la llegada de Francisco José.

${ }^{49}$ Le Figaro, 5 de julio de 1867, p. 1.

${ }^{50}$ Le Figaro, 6 de julio de 1867, p. 4.

${ }^{51}$ Le Mémorial Diplomatique. Journal international, politique, littéraire \& financier, 3 de julio de 1867, p. 6. Para más información sobre la Ley del 3 de Octubre de 1865, véase Jorge Mario Magallón Ibarra, "Ley del 3 de Octubre de Maximiliano", en Proceso y ejecución vs. Fernando Maximiliano de Habsburgo, 2005, México, UNAM, pp. 246ss. 
Para el Mémorial, la muerte de Maximiliano fue una represalia del gobierno mexicano por este decreto.

Cada informe recibido de México era una oportunidad para esclarecer el fusilamiento de Maximiliano. ${ }^{52}$ Enseguida, la entrega del cuerpo generó controversias, porque el cónsul austriaco en Nueva York, Loosey, informó que el gobierno de Juárez se rehusaba a entregar el cadáver embalsamado. ${ }^{53}$ El secretario particular de Maximiliano en México, José Luis Blasio, escribió en sus memorias que el cuerpo fue entregado al vicealmirante austriaco Tegetthoff a finales de 1867 y finalmente llevado a Viena a inicios de $1868 .^{54}$

Algunos periódicos exhibían una tendencia imperial y oficialista (Le Constitutionnel, Le Monde Illustré y Le Mémorial Diplomatique), otros eran partidarios de la oposición republicana (como Le Siècle) y algunos más liberales pero comprometidos con el régimen napoleónico (Le Figaro, Le Petit Journal y Le Temps). Sin embargo, todos favorecían la idea de que Maximiliano regresara con vida a Europa. Una ola de desinformación había inundado las páginas de los diarios y suscitó grandes esperanzas de salvarle la vida. Las inexactitudes permitieron la circulación de todo género de opiniones, pero una vez sabida la verdad, los periódicos se unieron para juzgar con parcialidad los hechos. Se descalificó y se propició una violencia verbal contra el gobierno mexicano. La prensa periódica parisina difundió relatos y versiones distintas sobre los actores del drama de Querétaro, que no siempre fueron coherentes.

${ }^{52}$ Solo he encontrado un folleto, publicado en Ginebra, en el que se defiende la causa republicana que representaba Juárez. Aunque se lamenta el fusilamiento de Maximiliano, se declara que él mismo buscó la muerte al intentar gobernar un país que ya tenía un gobierno propio. En el folleto se subraya que la pena fue impuesta por una corte marcial establecida legalmente. Cyprien Millot, Question Mexicaine. L'empereur est mort!, 1867, Ginebra, Imprimerie Pfeffer et Puky.

${ }^{53}$ Le Temps, 4 de julio de 1867, p. 1.

54 "El veinticinco de noviembre, en Veracruz el vicealmirante recibió oficialmente el cadáver de las autoridades y recogió las llaves del ataúd." José Luis Blasio, Maximiliano íntimo: el emperador Maximiliano y su corte. Memorias de un secretario particular, 1960, México, Editorial Nacional, p. 263. 
Se prohíbe su reproducción total o parcial por cualquier medio, incluido electrónico, sin permiso previo y por escrito de los editores. 